\title{
Do gaming disorder and hazardous gaming belong in the ICD-11? Considerations regarding the death of a hospitalized patient that was reported to have occurred while a care provider was gaming
}

\begin{abstract}
There has been much debate regarding the extent to which different types and patterns of gaming may be considered harmful from individual and public health perspectives. A recent event in which a hospitalized patient was reported to have died while a care provider was gaming is worth considering as an example as to how gaming may distract individuals from work-related tasks or other activities, with potential negative consequences. As the 11th edition of the International Classification of Diseases is being developed, events like these are important to remember when considering entities like, and generating criteria for, disordered or hazardous gaming.
\end{abstract}

Keywords: Internet gaming disorder, International Classification of Diseases, addiction, hazardous gaming, addictive behaviors, behavioral addictions

There has been considerable debate regarding how gaming behaviors might best be considered from a psychiatric perspective. Recent events involving the death of a hospitalized patient while a nurse's aide was reportedly playing a video game highlight the importance of considering different patterns and types of gaming behaviors (Estes, 2017). Over the past decade, psychiatrists and other mental health care providers have been encountering individuals seeking help for problems relating to video gaming. Raised concerns related to video gaming led to the inclusion in Section III of the fifth edition of the Diagnostic and Statistical Manual of Mental Disorders (DSM-5) criteria for Internet gaming disorder (IGD; American Psychiatric Association, 2013). The decision to focus on Internet gaming, over other behaviors, was based in part on the data existing at the time of DSM-5 deliberations that Internet gaming had been most well-studied and associated with significant harms (Petry \& O'Brien, 2013). The inclusion has led to the generation of more precise research of the condition and hopefully will lead to improved prevention and treatment strategies.

In the setting of the inclusion of IGD in Section III of DSM-5, there has been ongoing debate regarding the appropriateness of a diagnostic entity relating to gaming behaviors (Kiraly \& Demetrovics, 2017; van den Brink, 2017), with some scholars proposing that it is premature to have a formal entity for IGD (Aarseth et al., 2017; Dullur \& Starcevic, 2018) and others advocating for its inclusion in the forthcoming 11th edition of the International Classification of Diseases (ICD-11; Billieux et al., 2017; King et al., 2018; Saunders et al., 2017). At present, beta draft versions of criteria for gaming disorder (https://icd.who. int/dev11/1-m/en\#/http://id.who.int/icd/entity/1448597234; accessed on: November 10, 2017) and hazardous gaming (https://icd.who.int/dev11/1-m/en\#/https://icd.who.int/dev11/ l-m/en\#/http://id.who.int/icd/entity/1586542716; accessed on: November 10,2017$)$ exist on the ICD-11 website. As it is unclear whether the incident involving the patient's death was or was not related to IGD or subsyndromal levels of gaming, it appears important from a public health perspective to include both diagnostic and hazardous designations as currently being proposed for ICD-11 and is analogous to designations for other addictive behaviors (e.g., alcohol-use disorders and hazardous alcohol use as currently exist in the ICD-10). I believe that having these gaming-related entities defined and included in the ICD-11 is important and that it will hopefully help prevent occurrences like the reported video game-playing-associated death of a hospitalized patient and facilitate the development of prevention and treatment efforts. Furthermore, the consideration of hazardous use of digital technologies more broadly appears important to consider given accidents related to distracted operation of cars and other vehicles (Wilson \& Stimpson, 2010). It is important to gather data on these behaviors to guide the development of frameworks and interventions at individual and policy levels to promote public health (King et al., 2017; Kiraly et al., in press). Such efforts will require governments and public health agencies to prioritize systematic research into different types and patterns of gaming and the effects that they may have on individuals (Potenza, Higuchi, \& Brand, 2018).

Funding sources: This work was conducted with support from the National Center for Responsible Gaming. The content of the manuscript does not necessarily reflect the views of any of the funding agencies. 
Author's contribution: Dr. MNP generated the manuscript and is responsible for the content.

Conflict of interest: Dr. MNP declares no conflict of interest. He has consulted for and advised INSYS, Shire, RiverMend Health, Opiant/Lightlake Therapuetics, and Jazz Pharmaceuticals; has received research support from the Mohegan Sun Casino, the National Center for Responsible Gaming, and Pfizer; has participated in surveys, mailings, or telephone consultations related to drug addiction, impulse-control disorders or other health topics; has consulted for gambling and legal entities on issues related to impulse-control and addictive disorders; provides clinical care in the Connecticut Department of Mental Health and Addiction Services Problem Gambling Services Program; has performed grant reviews for the National Institutes of Health and other agencies; has edited journals or journal sections; has given academic lectures in grand rounds, CME events and other clinical or scientific venues; and has generated books or book chapters for publishers of mental health texts.

\section{REFERENCES}

Aarseth, E., Bean, A. M., Boonen, H., Colder Carras, M., Coulson, M., Das, D., Deleuze, J., Dunkels, E., Edman, J., Ferguson, C. J., Haagsma, M. C., Helmersson Bergmark, K., Hussain, Z., Jansz, J., Kardefelt-Winther, D., Kutner, L., Markey, P., Nielsen, R. K., Prause, N., Przybylski, A., Quandt, T., Schimmenti, A., Starcevic, V., Stutman, G., Van Looy, J., \& Van Rooij, A. J. (2017). Scholars' open debate paper on the World Health Organization ICD-11 gaming disorder proposal. Journal of Behavioral Addictions, 6(3), 267-270. doi:10.1556/ 2006.5.2016.088

American Psychiatric Association. (2013). Diagnostic and statistical manual of mental disorders (5th ed.). Washington, DC: American Psychiatric Press, Inc.

Billieux, J., King, D. L., Higuchi, S., Achab, S., Bowden-Jones, H., Hao, W., Long, J., Lee, H. K., Potenza, M. N., Saunders, J. B., \& Poznyak, V. (2017). Functional impairment matters in the screening and diagnosis of gaming disorder. Journal of Behavioral Addictions, 6(3), 285-289. doi:10.1556/2006.6. 2017.036

Dullur, P., \& Starcevic, V. (2018). Internet gaming disorder does not qualify as a mental disorder. Australian and New Zealand Journal of Psychiatry, 52, 110-111. doi:10.1177/000486741 7741554

Estes, A. (2017, October). A nurses' aide plays video games while a veteran dies at a Bedford VA hospital. The Boston Globe. Retrieved from https:/www.bostonglobe.com/metro/2017/10/ 17/nurse-aide-plays-video-games-while-vietnam-veteran-diesbedford-medical-center/IsWg0TU12q0mSoxgsa5eFM/story. html. Accessed on: November 10, 2017.
King, D. L., Delfabbro, P. H., Potenza, M. N., Demetrovics, Z., Billieux, J., \& Brand, M. (2018). Internet gaming disorder should qualify as a mental disorder. Australian and New Zealand Journal of Psychiatry, 52(2), 110-111. doi:10.1177/0004867417741554

King, D. L., Delfabbro, P. H., Wu, A. M. S., Doh, Y. Y., Kuss, D. J., Pallesen, S., Mentzoni, R., Carragher, N., \& Sakuma, H. (2017). Treatment of Internet gaming disorder: An international systematic review and CONSORT evaluation. Clinical Psychology Review, 54, 123-133. doi:10.1016/j.cpr.2017.04.002

Kiraly, O., \& Demetrovics, Z. (2017). Inclusion of gaming disorder in ICD has more advantages than disadvantages. Journal of Behavioral Addictions, 6(3), 280-284. doi:10.1556/2006.6. 2017.046

Kiraly, O., Griffiths, M. D., King, D. L., Kook, H. K., Lee, S. Y., Fanni, B., Agnes, Z., Takacsm, Z. K., \& Demetrovics, Z. (in press). Policy responses to problematic video game use: A systematic review of current measures and future possibilities. Journal of Behavioral Addictions. Advance online publication. Retrieved from https://akademiai.com/doi/abs/10.1556/2006. 6.2017.050. Accessed on: April 8, 2018.

Petry, N. M., \& O'Brien, C. P. (2013). Internet gaming disorder and the DSM-5. Addiction, 108, 1186-1187. doi:10.1111/add.12162

Potenza, M. N., Higuchi, S., \& Brand, M. (2018). Call for research into a wider range of behavioural addictions. Nature, 555, 30-30. doi:10.1038/d41586-018-02568-Z

Saunders, J. B., Hao, W., Long, J., King, D., Mann, K., Fauth-Bühler, M., Rumpf, H. J., Bowden-Jones, H., Rahimi-Movaghar, A., Chung, T., Chan, E., Bahar, N., Achab, S., Lee, H. K., Potenza, M. N., Petry, N., Spritzer, D., Ambekar, A., Billieux, J., Derevensky, J., Griffiths, M., Pontes, H., Kuss, D., Higuchi, S., Mihara, S., Assangangkornchai, S., Sharma, M., El Kashef, A., Ip, P., Farrell, M., Scafato, E., Carragher, N., \& Poznyak, V. (2017). Gaming disorder: Its delineation as an important condition for diagnosis, management and prevention. Journal of Behavioral Addictions, 6(3), 271-279. doi:10.1556/2006.6.2017.039

van den Brink, W. (2017). ICD-11 gaming disorder: Needed and just in time or dangerous and much too early? Journal of Behavioral Addictions, 6(3), 290-292. doi:10.1556/2006.6. 2017.040

Wilson, F. A., \& Stimpson, J. P. (2010). Trends in fatalities from distracted driving in the United States, 1999 to 2008. American Journal of Public Health, 100(11), 2213-2219. doi:10.2105/ AJPH.2009.187179

Marc N. Potenza, MD, PhD

Departments of Psychiatry and Neuroscience and the Child Study Center, Yale University School of Medicine,

New Haven, CT, USA The Connecticut Mental Health Center, New Haven,

CT, USA

Phone: +1 203974 7356; Fax: +1 2039747366

E-mail: marc.potenza@yale.edu 